\title{
What rheumatologists in the United States think of complementary and alternative medicine: results of a national survey
}

\author{
Nisha J Manek ${ }^{1 *}$, Cynthia S Crowson², Abigale L Ottenberg ${ }^{3}$, Farr A Curlin ${ }^{4}$, Ted J Kaptchuk ${ }^{5}$, Jon C Tilburt 3,6
}

\begin{abstract}
Background: We aimed to describe prevailing attitudes and practices of rheumatologists in the United States toward complementary and alternative medicine (CAM) treatments. We wanted to determine whether rheumatologists' perceptions of the efficacy of CAM therapies and their willingness to recommend them relate to their demographic characteristics, geographic location, or clinical practices.

Methods: A National Institutes of Health-sponsored cross-sectional survey of internists and rheumatologists was conducted regarding CAM for treatment of chronic back pain or joint pain. In this study we analyzed responses only from rheumatologists. Response items included participant characteristics and experience with 6 common CAM categories, as defined by the National Institutes of Health. Descriptive statistics were used to describe attitudes to CAM overall and to each CAM category. Composite responses were devised for respondents designating 4 or more of the 6 CAM therapies as "very" or "moderately" beneficial or "very likely" or "somewhat likely" to recommend.

Results: Of 600 rheumatologists who were sent the questionnaire, 345 responded (58\%); 80 (23\%) were women. Body work had the highest perceived benefit, with $70 \%$ of respondents indicating benefit. Acupuncture was perceived as beneficial by 54\%. Most were willing to recommend most forms of CAM. Women had significantly higher composite benefit and recommend responses than men. Rheumatologists not born in North America were more likely to perceive benefit of select CAM therapies.
\end{abstract}

Conclusions: In this national survey of rheumatologists practicing in the United States, we found widespread favorable opinion toward many, but not all, types of CAM. Further research is required to determine to what extent CAM can or should be integrated into the practice of rheumatology in the United States.

\section{Background}

Results of the National Health Interview Surveys in 2002 and 2007 showed that complementary and alternative medicine (CAM) use among patients with arthritis is very pervasive $[1,2]$. The odds ratio for ever-use of CAM among adults with arthritis was 1.59 compared with adults with no chronic diseases and was higher than CAM use among patients with any other common chronic diseases including cardiovascular disease and cancer [3]. It is clear, therefore, that patients' use of $\mathrm{CAM}$ is an important clinical issue; this is especially

\footnotetext{
* Correspondence: manek.nisha@mayo.edu

'Division of Rheumatology, Department of Medicine, Mayo Clinic, 200 First St., Rochester, MN 55905, USA
}

true for rheumatologists and primary care physicians who treat arthritis.

The relationship of physicians to CAM has been the subject of some international study. A meta-analysis by Ernst et al in 1995 [4] and a review by Astin et al in 1998 [5] have summarized this research. The proportion of mainstream physicians who incorporated some form of CAM into their own practices (drawn from 19 methodologically acceptable studies) ranged from $9 \%$ to $19 \%$, and CAM referral rates ranged from $4 \%$ to $43 \%$ [5]. More recent surveys from countries such as Italy and Germany indicate an increasing trend of primary physicians incorporating CAM into their practices [6,7].

In the past 5 years, the conventional medical community has shown increasing openness toward several

\section{(}

\section{()


CAM therapies. For example, much-awaited research on popular nutraceuticals, specifically on the use of glucosamine and chondroitin sulfate for knee osteoarthritis [8], has been published in prominent medical journals, but few positive results have been shown. These trends in increasing awareness of CAM in general have not been without controversy and highlight broader debates about what constitutes the scope of acceptable contemporary medical practice including rheumatology. These and other issues may affect whether rheumatologists consider referring their patients for CAM therapies or even using CAM in their clinical practice.

Rheumatology is often algorithm and protocol driven, and adherence to guidelines and strict standards of safety and efficacy is a professional expectation [9]. However, especially in an era of fewer safe therapeutic prescription options (eg, withdrawal of rofecoxib from the market in 2004), it is interesting to examine to what extent rheumatology specialists consider less-rigorously tested CAM modalities to be legitimate therapeutic elements in clinical practice.

We are aware of 1 published survey of rheumatologists in the United States that examined the extent to which physicians incorporated 22 CAM therapies into their professional practices [10]. This survey, undertaken in 2000, included questions about dietary prescriptions and exercise intervention, which are considered in the realm of conventional medical care [11].

In the current study, we surveyed rheumatologists in the United States and addressed several broad research questions. 1) What are the prevailing attitudes and practices of conventional rheumatologists regarding common types of CAM? 2) How do rheumatologists' perceptions of CAM efficacy and their willingness to recommend CAM relate to their demographics, geographic location, and clinical practices? 3) What variables predict rheumatologists' attitudes toward CAM?

\section{Methods}

\section{Participants}

As of 2005 and 2006, the total number of practicing rheumatologists in the United States was estimated to be 4,946 [12]. In the summer of 2007, a 12-page selfadministered questionnaire was mailed to a stratified random sample of 600 rheumatologists younger than 65 years in the United States as part of a larger national survey of health care providers' perceptions about CAM, which was sponsored by the National Institutes of Health. Details of the survey have been published elsewhere [13]. Participants were screened to determine if they were currently in practice. Using the standard conservative survey research definitions, response rates were calculated (RRI from the American Association for Public Opinion Research) [14]. This survey study was evaluated and declared exempt by the Mayo Clinic Institutional Review Board.

\section{Survey Instrument}

The survey was developed through a formal process which included focus groups, drafting of an instrument, cognitive testing, and further revision of the instrument, as described in detail previously [13]. The survey focused on the rheumatologists' opinions and use of 6 common CAM therapies: spinal manipulation (eg, chiropractic care), acupuncture, energy medicine (eg, Reiki), meditation practice (eg, yoga), glucosamine and/or chondroitin, and body work (eg, massage, shiatsu). These 6 CAM groups were drawn from existing National Institutes of Health categories of CAM and from testing of physicians' degree of familiarity during focus groups.

\section{Independent Variables}

Respondents reported their demographic information including age, sex, region of birth (North America, Central/South America/Caribbean, Europe/Australia, Middle East, Africa, Asia/Pacific Islands), race, rheumatology practice characteristics (solo, private; group, private; institutional, private; academic), and region of practice in the United States.

\section{Dependent Variables}

We measured 2 dimensions of physicians' attitudes toward integrating CAM into their clinical practice. These were 1) perceived benefit and 2) likelihood of recommending each of the 6 CAM therapies for treatment of chronic back pain or joint pain. Perceived benefit of each of the CAM therapies was surveyed with the questionnaire item: "How beneficial do you think each of these therapies is for chronic back pain or joint pain?" A 4-point scale with response categories "very," "moderately," "not very," or "not at all" beneficial was used.

Similarly, likelihood of recommending each CAM therapy was surveyed with the questionnaire item: "How likely would you be to recommend each of these therapies as one component of a comprehensive treatment package for patients with chronic back pain or joint pain?" A 4-point scale with response categories "very likely to," "somewhat likely to," "not very likely to," and "would never" recommend was used.

\section{Data Management and Analysis}

Descriptive statistics were used to summarize the data. Cronbach's $\alpha$ was used to measure how well the variables of perceived benefit of and likelihood of recommending CAM modalities were interrelated.

Proportional odds models (an extension of logistic regression allowing more than 2 ordered categories for the outcome) for each of the 6 CAM modalities using a 0 to 3-point scale were used to examine how rheumatologists' perceptions of the benefit of CAM and their willingness to recommend CAM relate to their demographic, 
geographic, and clinical practice characteristics. The proportional odds assumption was examined using the score test and was not violated.

A composite response variable was used to analyze which characteristics of rheumatologists are independently associated with their attitudes toward CAM overall by using responses to items for individual types of CAM. In this case, perceived benefit was defined as respondents indicating 4 or more of the 6 CAM therapies as being either "very beneficial" or "moderately beneficial." Similarly, a composite response was defined for the likelihood of recommending CAM, defined as respondents indicating that they were either "very likely" or "somewhat likely" to recommend 4 or more of the 6 CAM therapies. Multivariate logistic regression models were used to examine the association between these composite responses and the independent variables of interest. For all tests of association, a 2-tailed alpha, $P<$ .05 was considered significant.

\section{Results}

Of the 600 rheumatologists in the United States randomly sampled, 345 (58\%) responded to the survey. The mean age of the respondents was 52 years (range, 25-65 years), $80(23 \%)$ were women, and the majority $(89 \%)$ were white (Table 1). This demographic distribution of the respondents was comparable to the national estimates of rheumatologists in 2005, with a median age of 51 years and 30\% female practitioners [12]. Most of the rheumatologists worked in a group practice setting (46\%), followed by solo practice (28\%), academic (20\%), and institutional (3\%) settings. A plurality of respondents $(140,41 \%)$ practiced in the Northeast region of the United States (Table 1$)$. The majority $(82 \%)$ of the rheumatologists responding were born in North America. Respondents and nonrespondents did not differ by age, race, sex, practice setting, or geographic location.

Rheumatologists' responses to perceived benefit of each CAM therapy are shown in Figure 1. The CAM modality with the highest perceived benefit was body work (practices such as massage), with $70 \%$ of respondents indicating that this was either "very beneficial" or "moderately beneficial"; the modality with the next highest perceived benefit was meditation at $63 \%$. More than half of all respondents perceived acupuncture (54\%) and spinal manipulation (52\%) to be either "very" or "moderately" beneficial. Glucosamine and/or chondroitin was perceived as beneficial by less than half of the rheumatologists, with more than half $(60 \%)$ indicating that this was either "not very" or "not at all" beneficial.

Rheumatologists were "very" or "somewhat likely" to recommend body work (65\%), followed closely by meditation (64\%) (Figure 2). More than half of all respondents were likely to recommend glucosamine and/or
Table 1 Characteristics of 345 Rheumatologists Responding

\begin{tabular}{lc}
\hline Characteristic $^{\text {a }}$ & Value $^{\text {b }}$ \\
\hline Mean (range) age, $y$ & $52(28-65)$ \\
Female sex & $80(23)$ \\
Race $(\mathrm{n}=333)$ & \\
Asian & $30(9)$ \\
Black & $3(1)$ \\
White & $296(89)$ \\
Other & $4(1)$ \\
Practice Setting $(\mathrm{n}=342)$ & \\
Solo & $97(28)$ \\
Group & $157(46)$ \\
Institutional & $11(3)$ \\
Academic & $68(20)$ \\
Other & $9(3)$ \\
Region & \\
Northeast & $140(41)$ \\
South & $136(39)$ \\
Midwest & $41(12)$ \\
West & $28(8)$ \\
Place of Birth $(\mathrm{n}=332)$ & \\
North America & $272(82)$ \\
Other & $60(18)$ \\
\hline
\end{tabular}

${ }^{a}$ No. of respondents answering the question is indicated if less than 345 .

${ }^{\mathrm{b}}$ No. of respondents (\%) unless otherwise indicated.

chondroitin (57\%) and acupuncture (54\%). Only 10\% of rheumatologists would consider recommending an energy medicine modality (such as Reiki).

The responses for the 6 CAM modalities regarding perceived benefit were highly correlated (Cronbach's $\alpha=0.76$ ), as were the responses for the 6 CAM modalities regarding recommendation for therapy (Cronbach's $\alpha=0.78$ ).

Multivariate analysis for each category of CAM therapy is shown in Table 2. Rheumatologists in institutional practice settings were more likely to perceive benefit of spinal manipulation and body work compared with their counterparts in other practice settings. However, the number of respondents in institutional practice was small $(\mathrm{n}=11)$, and the result was not significant when the categories "other" and "institutional practice" were combined. Women rheumatologists were significantly more likely than men to perceive the benefit of meditation practices $(P<.001)$, glucosamine and/or chondroitin $(P=.003)$, and body work $(P=.01)$. Also, rheumatologists practicing in the South $(P=.05)$ and those not born in North America $(P=.04)$ were more likely to perceive the benefit of meditation practices.

Composite analyses of individual CAM modality ratings showed that 124 of 326 rheumatologists (38\%) viewed CAM overall as beneficial (defined as rating 4 or more of the 6 CAM modalities as "very beneficial" or 


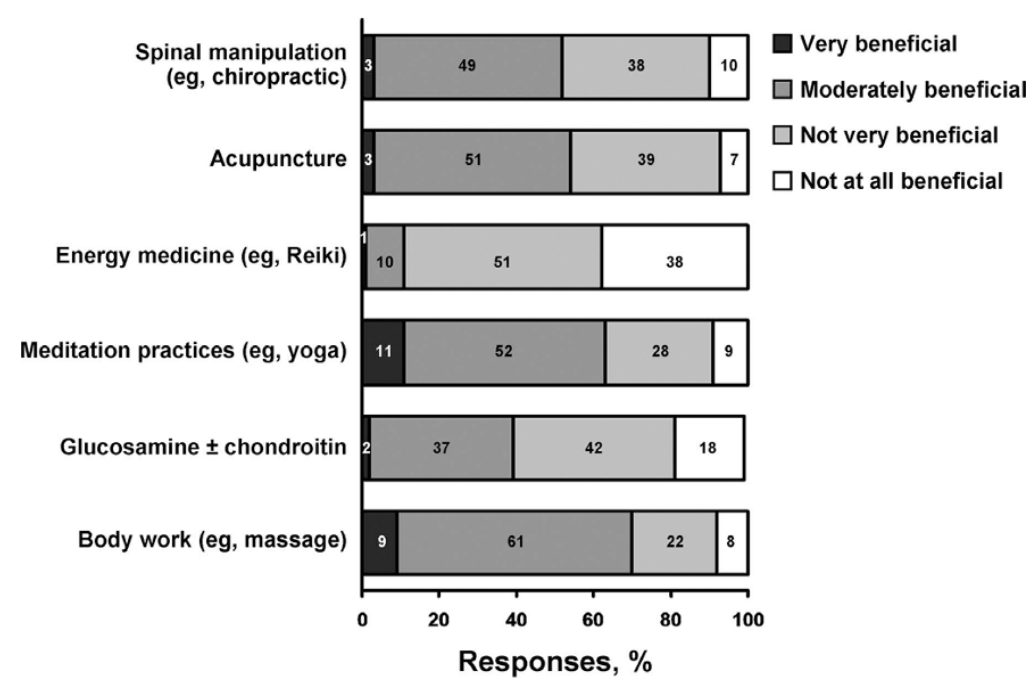

Figure 1 Survey responses of rheumatologists. Views of respondents regarding the benefit of various types of complementary and alternative medicine.

"moderately beneficial"), and 132 of 330 rheumatologists (40\%) were willing to recommend CAM therapies (defined as rating 4 or more of the 6 CAM modalities as "very likely" or "somewhat likely" to recommend).

Sex was significantly associated with higher composite "benefit" response $(P=.02)$ (Table 3$)$. Women rheumatologists were more likely to rate CAM therapies as beneficial than were men. Rheumatologists not born in North America were more likely to recommend CAM therapies $(P=.008)$. No significant differences in benefit or recommend responses were seen for practice setting or geographic region of the United States. Although the association did not reach statistical significance, rheumatologists in the South were slightly more likely to recommend CAM therapies $(P=.07)$.

\section{Discussion}

Results of this national survey showed that most rheumatologists express favorable attitudes toward most categories of CAM practices relevant to the care of patients with chronic back pain or joint pain. More than half of the respondents consider common individual CAM therapies to be beneficial and are at least moderately likely to recommend them. However, rheumatologists'

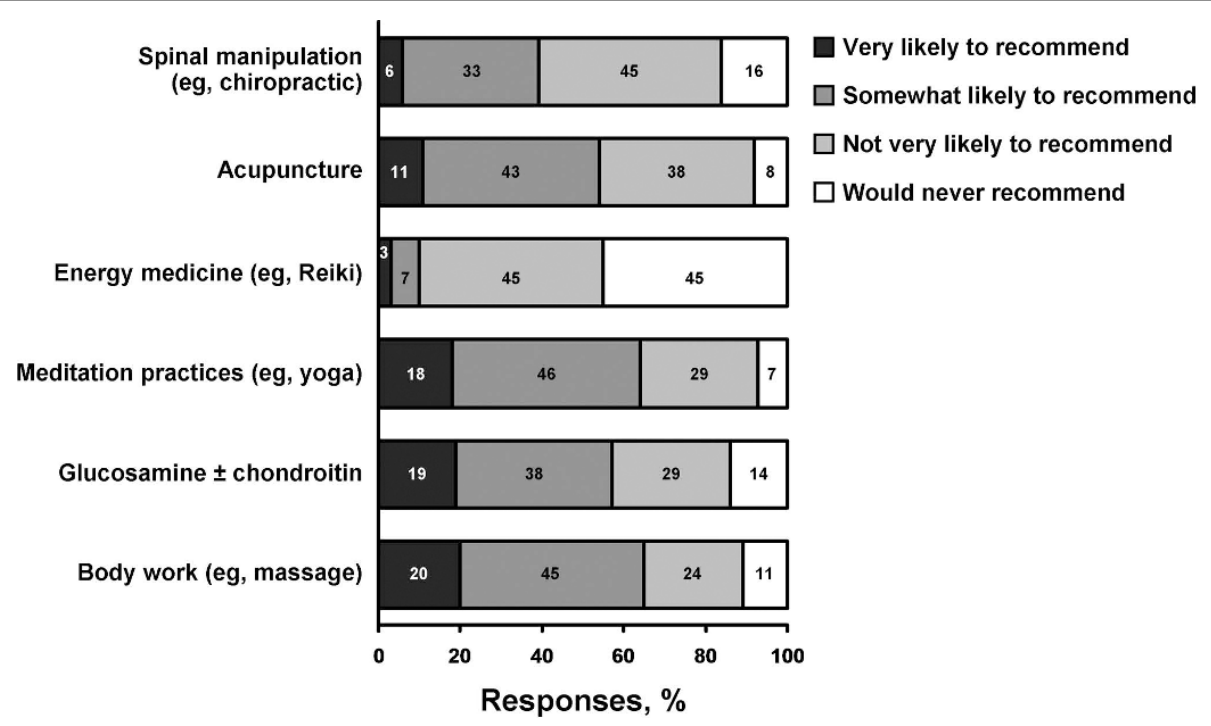

Figure 2 Survey responses of rheumatologists. Views of respondents regarding their willingness to recommend various types of complementary and alternative medicine. 
Table 2 Associations Between Characteristics of Rheumatologists and Responses Regarding Perceived Benefit of Each CAM Therapy

\begin{tabular}{|c|c|c|c|c|c|c|}
\hline \multirow[b]{2}{*}{ Characteristic } & \multicolumn{6}{|c|}{ OR $(95 \% \mathrm{Cl})^{\mathrm{a}}$} \\
\hline & Spinal Manipulation & Acupuncture & Energy Medicine & Meditation & $\mathrm{G} \pm \mathrm{C}$ & Body Work \\
\hline Age (per 10 y) & $\begin{array}{c}0.8 \\
(0.6-1.1)\end{array}$ & $\begin{array}{c}0.8 \\
(0.6-1.1)\end{array}$ & $\begin{array}{c}0.8 \\
(0.6-1.2)\end{array}$ & $\begin{array}{c}0.8 \\
(0.6-1.1)\end{array}$ & $\begin{array}{c}1.0 \\
(0.8-1.3)\end{array}$ & $\begin{array}{c}0.9 \\
(0.6-1.2)\end{array}$ \\
\hline Sex (Female) & $\begin{array}{c}1.5 \\
(0.9-2.6)\end{array}$ & $\begin{array}{c}1.4 \\
(0.8-2.4)\end{array}$ & $\begin{array}{c}2.0 \\
(0.98-4.0)\end{array}$ & $\begin{array}{c}2.6 \\
(1.5-4.6)\end{array}$ & $\begin{array}{c}2.3 \\
(1.3-3.9)\end{array}$ & $\begin{array}{c}2.2 \\
(1.2-4.0)\end{array}$ \\
\hline Race (White) & $\begin{array}{c}1.1 \\
(0.5-2.7)\end{array}$ & $\begin{array}{c}0.8 \\
(0.3-1.9)\end{array}$ & $\begin{array}{c}1.4 \\
(0.5-4.3)\end{array}$ & $\begin{array}{c}1.7 \\
(0.7-4.2)\end{array}$ & $\begin{array}{c}0.7 \\
(0.3-1.5)\end{array}$ & $\begin{array}{c}1.4 \\
(0.5-3.5)\end{array}$ \\
\hline Practice Setting (vs Solo) & $P=.45$ & $P=.66$ & $P=.87$ & $P=.34$ & $P=.25$ & $P=.30$ \\
\hline Group & $\begin{array}{c}1.4 \\
(0.8-2.4)\end{array}$ & $\begin{array}{c}0.9 \\
(0.5-1.6)\end{array}$ & $\begin{array}{c}1.0 \\
(0.6-2.0)\end{array}$ & $\begin{array}{c}0.8 \\
(0.5-1.4)\end{array}$ & $\begin{array}{c}1.3 \\
(0.8-2.2)\end{array}$ & $\begin{array}{c}1.2 \\
(0.7-2.1)\end{array}$ \\
\hline Institutional/Other & $\begin{array}{c}1.0 \\
(0.4-2.6)\end{array}$ & $\begin{array}{c}0.6 \\
(0.2-1.7)\end{array}$ & $\begin{array}{c}1.1 \\
(0.3-3.6)\end{array}$ & $\begin{array}{c}1.2 \\
(0.4-3.4)\end{array}$ & $\begin{array}{c}1.0 \\
(0.4-2.7)\end{array}$ & $\begin{array}{c}2.4 \\
(0.8-7.3)\end{array}$ \\
\hline Academic & $\begin{array}{c}0.9 \\
(0.5-1.8)\end{array}$ & $\begin{array}{c}1.2 \\
(0.6-2.3)\end{array}$ & $\begin{array}{c}0.8 \\
(0.4-1.7)\end{array}$ & $\begin{array}{c}0.6 \\
(0.3-1.1)\end{array}$ & $\begin{array}{c}1.9 \\
(1.0-3.6)\end{array}$ & $\begin{array}{c}0.8 \\
(0.4-1.7)\end{array}$ \\
\hline Region (vs Northeast) & $P=.98$ & $P=.60$ & $P=.59$ & $P=.05$ & $P=.63$ & $P=.29$ \\
\hline South & $\begin{array}{c}1.0 \\
(0.6-1.6)\end{array}$ & $\begin{array}{c}0.9 \\
(0.6-1.5)\end{array}$ & $\begin{array}{c}0.9 \\
(0.5-1.7)\end{array}$ & $\begin{array}{c}1.7 \\
(1.01-2.7)\end{array}$ & $\begin{array}{c}1.7 \\
(1.02-2.7)\end{array}$ & $\begin{array}{c}1.9 \\
(1.1-3.2)\end{array}$ \\
\hline Midwest & $\begin{array}{c}0.9 \\
(0.4-1.8)\end{array}$ & $\begin{array}{c}0.7 \\
(0.3-1.5)\end{array}$ & $\begin{array}{c}0.6 \\
(0.3-1.4)\end{array}$ & $\begin{array}{c}0.7 \\
(0.3-1.5)\end{array}$ & $\begin{array}{c}1.7 \\
(0.8-3.5)\end{array}$ & $\begin{array}{c}1.2 \\
(0.6-2.6)\end{array}$ \\
\hline West & $\begin{array}{c}0.6 \\
(0.3-1.4)\end{array}$ & $\begin{array}{c}0.6 \\
(0.3-1.5)\end{array}$ & $\begin{array}{c}0.9 \\
(0.3-2.3)\end{array}$ & $\begin{array}{c}0.8 \\
(0.4-1.9)\end{array}$ & $\begin{array}{c}1.1 \\
(0.5-2.5)\end{array}$ & $\begin{array}{c}1.0 \\
(0.4-2.6)\end{array}$ \\
\hline Place of Birth (not North America) & $\begin{array}{c}1.0 \\
(0.5-2.2)\end{array}$ & $\begin{array}{c}1.2 \\
(0.6-2.5)\end{array}$ & $\begin{array}{c}1.5 \\
(0.6-3.7)\end{array}$ & $\begin{array}{c}2.2 \\
(1.02-4.5)\end{array}$ & $\begin{array}{c}1.0 \\
(0.5-2.1)\end{array}$ & $\begin{array}{c}1.8 \\
(0.8-4.0)\end{array}$ \\
\hline
\end{tabular}

Abbreviations: $\mathrm{C}$, chondroitin; CAM, complementary and alternative medicine; $\mathrm{Cl}$, confidence interval; $\mathrm{G}$, glucosamine; OR, odds ratio.

a OR for an ordinal response of "very," "moderately," "not very," or "not at all" beneficial. Bolded entries indicate statistical significance.

opinions regarding perceived benefit of common CAM therapies and their likelihood of recommending them varied widely across different CAM modalities; percentage of favorable responses ranged from as high as $70 \%$ for body work to as low as $11 \%$ for energy medicine. After controlling for other factors, female sex and being born outside the United States were independently associated with rheumatologists' favorable ratings of perceived benefit and willingness to recommend CAM.

Because chronic musculoskeletal conditions are a leading indication for the use of CAM, rheumatologists have been urged to discuss CAM with their patients [15]. Provider attitudes seem to be becoming more favorable; a recent study suggests that if rheumatologists use more participatory styles of decision making with patients, patients are more likely to tell them about their CAM use [16]. The main result of our study contributes to the literature from the providers' perspective in that the historical antagonism between CAM practitioners and mainstream rheumatology physicians seems weakened.

We found that female rheumatologists were twice as likely to perceive benefit of common CAM therapies as their male counterparts, a result that is consistent with some but not all previous surveys of other physician groups [17-20]. Sex has been of no clear significance in other studies [21-23]. Although we had no particular a priori hypothesis about a sex difference, it is possible that women, who are more favorably disposed to CAM in general, may carry over that attitude into their professional attitudes [24]. Furthermore, these data showing a sex difference at least suggest that core physician characteristics are integral to their attitudes and clinical reasoning about CAM that cannot be ignored.

Other factors associated with favorable attitudes toward CAM are not well explained from this exploratory study. Although their numbers were small, rheumatologists practicing in an institutional practice were more likely to perceive benefit from spinal manipulation and body work compared with their colleagues in group and academic settings. The reasons for this are not clear from our data. Large institutional practices may incorporate certain CAM treatments into their programs based on the availability of certified practitioners in their area or may have arrangements for reimbursement for particular CAM therapies, thus making it easier for physicians to access and gain a level of familiarity with these practices. It is quite likely that consumer demand for CAM is motivating more insurers and hospitals to incorporate CAM [25-27], which may differentially affect institutional practices.

Results from this national survey did not show regional variations in attitudes toward CAM treatments 
Table 3 Multivariate Associations Between Characteristics of Rheumatologists and Responses Regarding Perceived Benefit and Likelihood of Recommending CAM

OR $(95 \% \mathrm{Cl})$

\begin{tabular}{|c|c|c|}
\hline Characteristic & Benefit $^{a}$ & Recommend $^{b}$ \\
\hline Age (per 10 y) & $\begin{array}{c}0.9 \\
(0.7-1.3)\end{array}$ & $\begin{array}{c}0.8 \\
(0.6-1.1)\end{array}$ \\
\hline Sex (Female) & $\begin{array}{c}1.9 \\
(1.1-3.4)\end{array}$ & $\begin{array}{c}1.7 \\
(0.9-2.9)\end{array}$ \\
\hline Race (White) & $\begin{array}{c}1.3 \\
(0.5-3.2)\end{array}$ & $\begin{array}{c}1.5 \\
(0.6-4.0)\end{array}$ \\
\hline Practice Setting (vs Solo) & $P=.65$ & $P=.67$ \\
\hline Group & $\begin{array}{c}0.9 \\
(0.5-1.6)\end{array}$ & $\begin{array}{c}1.3 \\
(0.7-2.3)\end{array}$ \\
\hline Institutional/Other & $\begin{array}{c}1.3 \\
(0.5-3.8)\end{array}$ & $\begin{array}{c}0.8 \\
(0.3-2.6)\end{array}$ \\
\hline Academic & $\begin{array}{c}0.7 \\
(0.3-1.4)\end{array}$ & $\begin{array}{c}1.0 \\
(0.5-1.9)\end{array}$ \\
\hline Region (vs Northeast) & $P=.49$ & $P=.07$ \\
\hline South & $\begin{array}{c}1.3 \\
(0.8-2.2)\end{array}$ & $\begin{array}{c}1.6 \\
(0.9-2.7)\end{array}$ \\
\hline Midwest & $\begin{array}{c}1.5 \\
(0.7-3.4)\end{array}$ & $\begin{array}{c}0.8 \\
(0.3-1.8)\end{array}$ \\
\hline West & $\begin{array}{c}0.8 \\
(0.3-2.1)\end{array}$ & $\begin{array}{c}0.6 \\
(0.2-1.7)\end{array}$ \\
\hline Place of Birth (not North America) & $\begin{array}{c}1.8 \\
(0.8-4.0)\end{array}$ & $\begin{array}{c}2.5 \\
(1.1-5.6)\end{array}$ \\
\hline
\end{tabular}

Abbreviations: CAM, complementary and alternative medicine; $\mathrm{Cl}$,

confidence interval; OR, odds ratio.

a OR for a composite response of 4 or more of 6 CAM therapies rated as "very" or "moderately" beneficial vs 3 or fewer of 6 CAM therapies with the same responses. Bolded entries indicate statistical significance.

${ }^{\mathrm{b}}$ OR for a composite response of 4 or more of 6 CAM therapies rated as "very likely" or "somewhat likely" to recommend vs 3 or fewer of 6 CAM therapies with the same responses. Bolded entries indicate statistical significance.

according to geographic region of the United States. This is consistent with a study by Borkan et al [21], which did not identify a significant difference in belief of effectiveness of CAM among practice locations in the United States. Further corroboration is provided by another study showing that a physician's country of origin did not have a significant effect on his or her belief in CAM [23]. We did, however, find that rheumatologists born outside the United States had more favorable attitudes toward CAM overall. This may reflect ethnic familiarity with some CAM therapies such as meditation.

We found a gradient of acceptance of CAM. Only $11 \%$ of respondents considered energy medicine beneficial, and physicians were less likely to recommend treatments such as Reiki. This may reflect to some extent the availability of, or experience with, energy medicine. Also, research in the area of energy medicine is lacking compared with other CAM therapies such as chiropractic, acupuncture, and body work, which may equally influence the lack of legitimacy ascribed to this category of CAM treatment. It is also possible that physicians have difficulty believing in a therapy that they view as scientifically implausible. It is worth noting that the CAM modalities that were most favored are those that appear most regularly in the popular media, which, to some extent, may influence physician choices $[28,29]$.

This study raises larger questions that remain unanswered. For instance, should CAM be "integrated" into the routine treatment options of rheumatologists? If an integrated approach is to be developed that allows a combination of the best of conventional medicine and CAM to provide an informed choice for patients with osteoarthritis, then it must be research led and evidence based. Signs show that CAM is becoming increasingly integrated. The number of randomized trials of CAM treatments is increasing, and the Cochrane Library now includes more than 200 reviews of complementary medicine interventions.

One consequence of the increase in the availability of high-quality data is that guidelines and consensus statements published by conventional medical bodies have supported the value of CAM. For example, current Osteoarthritis Research Society International guidelines list acupuncture and glucosamine with or without chondroitin as nonpharmacologic treatment for hip and knee osteoarthritis [9]. Therefore, it appears that one stimulus for increasing integration has been the increase in research evidence. Nevertheless, many unanswered questions remain before a truly integrated practice of rheumatology would be practically possible, including potential attitudinal trends among rheumatologists themselves.

Notable strengths of this study include a random (representative) sampling of rheumatology providers from defined areas of the United States. This provides a comprehensive view of rheumatology specialist attitudes, whereas previous surveys have mostly focused on primary care providers $[6,7,17,19,22,23]$. The reliability of the questions in this survey has been rigorously tested. Aspects not previously studied that can influence physician perceptions of CAM, such as ethnic background, practice setting, and geographical region, were examined. Previous physician surveys have tended to define CAM in various ways, from as few as 3 modalities to as many as 25 . The definition of CAM in this survey was based on well-described categories by the National Institutes of Health, thus enhancing interpretation of data.

Some limitations of this survey include the quantitative nature of data gathering. A close-ended survey style does not allow for description of the "art of medicine" and decision making. A qualitative study would allow rheumatologists the opportunity to describe and discuss the manner in which they manage common musculoskeletal conditions on a day-to-day basis [30]. This study 
was cross-sectional, and as CAM therapies evolve and more studies are published, the trend of physician attitudes will likely change. It is important to note that our results may not be generalizable to physicians on the West Coast because the sample of respondents was small compared with that from the Northeast. Additionally, we do not know how physician attitudes may shift and change when treating particular rheumatologic conditions other than osteoarthritis. The response rate of $58 \%$ could potentially exaggerate response bias, but responders and nonresponders did not differ significantly. We included only common CAM therapies, potentially underestimating the prevalence of true CAM usage. The incorporation of questions on placebo prescribing could potentially affect the attitudes of the physician toward CAM. Other important considerations that potentially affect rheumatologists' attitudes toward CAM in formulating a treatment recommendation, including patient preferences, clinical experience, and published research, will be addressed in a subsequent analysis.

\section{Conclusions}

The results of this exploratory survey suggest that there is widespread favorable opinion toward many, but not all, types of CAM therapies. The degree to which rheumatologists are likely to consider CAM in formulating a treatment recommendation relates to different aspects of their background, especially sex, country of birth, and characteristics of their practice (eg, institutional practice setting). If CAM therapies are to be more fully integrated into the practice of rheumatology, we need a more extensive assessment of how the modes of reasoning and therapeutic modalities of many CAM traditions can fit in with the diagnostic and therapeutic categories of contemporary rheumatology practice.

\section{Abbreviations \\ CAM: complementary and alternative medicine.}

\begin{abstract}
Author details
${ }^{1}$ Division of Rheumatology, Department of Medicine, Mayo Clinic, 200 First St., Rochester, MN 55905, USA. ${ }^{2}$ Division of Biomedical Statistics and Informatics, Mayo Clinic, 200 First St., Rochester, MN 55905, USA. ${ }^{3}$ Bioethics Research Program. Mayo Clinic, 200 First St., Rochester, MN 55905, USA.

${ }^{4}$ Section of Internal Medicine and the MacLean Center for Clinical Medical Ethics, The University of Chicago, 5758 S. Maryland Ave, Chicago, IL 60637 . USA. ${ }^{5}$ Osher Research Center, Harvard Medical School, 401 Park Dr., Boston, MA 02215, USA. ${ }^{6}$ Division of General Internal Medicine, Department of Medicine, Mayo Clinic, 200 First St., Rochester, MN 55905, USA.
\end{abstract}

\section{Authors' contributions}

N.J.M. carried out preparation of the manuscript; C.S.C. performed the statistical analysis; A.L.O. helped in the draft of the manuscript. F.A.C. participated in design of the survey and helped draft the manuscript. T.J.K. participated in design of the survey and helped to draft the manuscript. J.C. T. participated in design of the study and helped to draft the manuscript. All authors read and approved the final manuscript.

\section{Competing interests}

The authors declare that they have no competing interests.

Received: 24 June 2009

Accepted: 28 January 2010 Published: 28 January 2010

\section{References}

1. Quandt SA, Chen H, Grzywacz JG, Bell RA, Lang W, Arcury TA: Use of complementary and alternative medicine by persons with arthritis: results of the National Health Interview Survey. Arthritis Rheum 2005, 53(5):748-55.

2. Barnes P, Heyman KM: Early release of selected estimates based on data from the January-June 2007 National Health Interview Survey. National Center for Health Statistics 2007http://www.cdc.gov/nchs/, December 2007.

3. Saydah $\mathrm{SH}$, Eberhardt MS: Use of complementary and alternative medicine among adults with chronic diseases: United States 2002. J Altern Complement Med 2006, 12(8):805-12.

4. Ernst $\mathrm{E}$, Resch $\mathrm{KL}$, White AR: Complementary medicine. What physicians think of it: a meta-analysis. Arch Intern Med 1995, 155(22):2405-8.

5. Astin JA, Marie A, Pelletier KR, Hansen E, Haskell WL: A review of the incorporation of complementary and alternative medicine by mainstream physicians. Arch Intern Med 1998, 158(21):2303-10.

6. Giannelli M, Cuttini M, Da Fre M, Buiatti E: General practitioners' knowledge and practice of complementary/alternative medicine and its relationship with life-styles: a population-based survey in Italy. BMC Fam Pract 2007, 8:30.

7. Joos S, Musselmann B, Szecsenyi J: Integration of Complementary and Alternative Medicine into Family Practices in Germany: Results of a National Survey. Evid Based Complement Alternat Med 2009.

8. Clegg DO, Reda DJ, Harris CL, Klein MA, O'Dell JR, Hooper MM, et al: Glucosamine, chondroitin sulfate, and the two in combination for painful knee osteoarthritis. N Engl J Med 2006, 354(8):795-808.

9. Zhang W, Moskowitz RW, Nuki G, Abramson S, Altman RD, Arden N, et al: OARSI recommendations for the management of hip and knee osteoarthritis, part I: critical appraisal of existing treatment guidelines and systematic review of current research evidence. Osteoarthritis Cartilage 2007, 15(9):981-1000, Epub 2007 Aug 27.

10. Berman BM, Bausell RB, Lee WL: Use and referral patterns for 22 complementary and alternative medical therapies by members of the American College of Rheumatology: results of a national survey. Arch Intern Med 2002, 162(7):766-70.

11. American College of Rheumatology Subcommittee on Osteoarthritis Guidelines: Recommendations for the medical management of osteoarthritis of the hip and knee: 2000 update. Arthritis Rheum 2000, 43(9):1905-15.

12. The Lewin Group: Workforce study of rheumatologists: final report. Atlanta (GA): The American College of Rheumatology 2006.

13. Tilburt JC, Emanuel EJ, Kaptchuk TJ, Curlin FA, Miller FG: Prescribing "placebo treatments": results of national survey of US internists and rheumatologists. BMJ 2008, 337:a1938.

14. American Association for Public Opinion Research: Standard definitions: final dispositions of case codes and outcome rates for surveys. Lenexa (KS): AAPOR, 42006

15. Perlman Al, Eisenberg DM, Panush RS: Talking with patients about alternative and complementary medicine. Rheum Dis Clin North Am 1999, 25(4):815-22.

16. Sleath B, Callahan LF, Devellis RF, Beard A: patients' perceptions of rheumatologists' participatory decision-making style and communication about complementary and alternative medicine. Arthritis Rheum 2008, 59(3):Arthritis416-21.

17. Kurtz ME, Nolan RB, Rittinger WJ: Primary care physicians' attitudes and practices regarding complementary and alternative medicine. J Am Osteopath Assoc 2003, 103(12):597-602.

18. Sikand A, Laken M: Pediatricians' experience with and attitudes toward complementary/alternative medicine. Arch Pediatr Adolesc Med 1998, 152(11):1059-64

19. Wahner-Roedler DL, Vincent A, Elkin PL, Loehrer LL, Cha SS, Bauer BA: Physicians' attitudes toward complementary and alternative medicine and their knowledge of specific therapies: a survey at an academic medical center. Evid Based Complement Alternat Med 2006, 3(4):495-501, Epub 2006 Jun 21 
20. Brown S: Use of complementary and alternative medicine by physicians in St. Petersburg, Russia. J Altern Complement Med 2008, 14(3):315-9.

21. Borkan J, Neher JO, Anson O, Smoker B: Referrals for alternative therapies. J Fam Pract 1994, 39(6):545-50

22. Anderson $E$, Anderson P: General practitioners and alternative medicine. $J$ $R$ Coll Gen Pract 1987, 37(295):52-5.

23. Schachter L, Weingarten MA, Kahan EE: Attitudes of family physicians to nonconventional therapies: a challenge to science as the basis of therapeutics. Arch Fam Med 1993, 2(12):1268-70.

24. Barnes PM, Powell-Griner E, MCFann K, Nahin RL: Complementary and alternative medicine use among adults: United States, 2002. Adv Data 2004, 343: 1-19.

25. Pelletier KR, Marie A, Krasner M, Haskell WL: Current trends in the integration and reimbursement of complementary and alternative medicine by managed care, insurance carriers, and hospital providers. Am J Health Promot 1997, 12(2):112-22.

26. Pelletier KR, Astin JA, Haskell WL: Current trends in the integration and reimbursement of complementary and alternative medicine by managed care organizations (MCOs) and insurance providers: 1998 update and cohort analysis. Am J Health Promot 1999, 14(2):125-33.

27. Cleary-Guida MB, Okvat HA, Oz MC, Ting W: A regional survey of health insurance coverage for complementary and alternative medicine: current status and future ramifications. J Altern Complement Med 2001 7(3):269-73.

28. Bonevski B, Wilson A, Henry DA: An analysis of news media coverage of complementary and alternative medicine. PLOS ONE 2008, 3(6):e2406.

29. Weeks LC, Strudsholm T: A scoping review of research on complementary and alternative medicine (CAM) and the mass media: looking back, moving forward. BMC Complement Altern Med 2008, 8:43.

30. Hamilton JL, Roemheld-Hamm B, Young DM, Jalba M, DiCicco-Bloom B: Complementary and alternative medicine in US family medicine practices: a pilot qualitative study. Altern Ther Health Med 2008, 14(3):22-7.

\section{Pre-publication history}

The pre-publication history for this paper can be accessed here:http://www. biomedcentral.com/1472-6882/10/5/prepub

doi:10.1186/1472-6882-10-5

Cite this article as: Manek et al: What rheumatologists in the United States think of complementary and alternative medicine: results of a national survey. BMC Complementary and Alternative Medicine 2010 10:5.

\section{Submit your next manuscript to BioMed Central and take full advantage of:}

- Convenient online submission

- Thorough peer review

- No space constraints or color figure charges

- Immediate publication on acceptance

- Inclusion in PubMed, CAS, Scopus and Google Scholar

- Research which is freely available for redistribution 